\title{
Cómo la creación de valor y la sustentabilidad convergen: \\ El gran desafío de la empresa actual
}

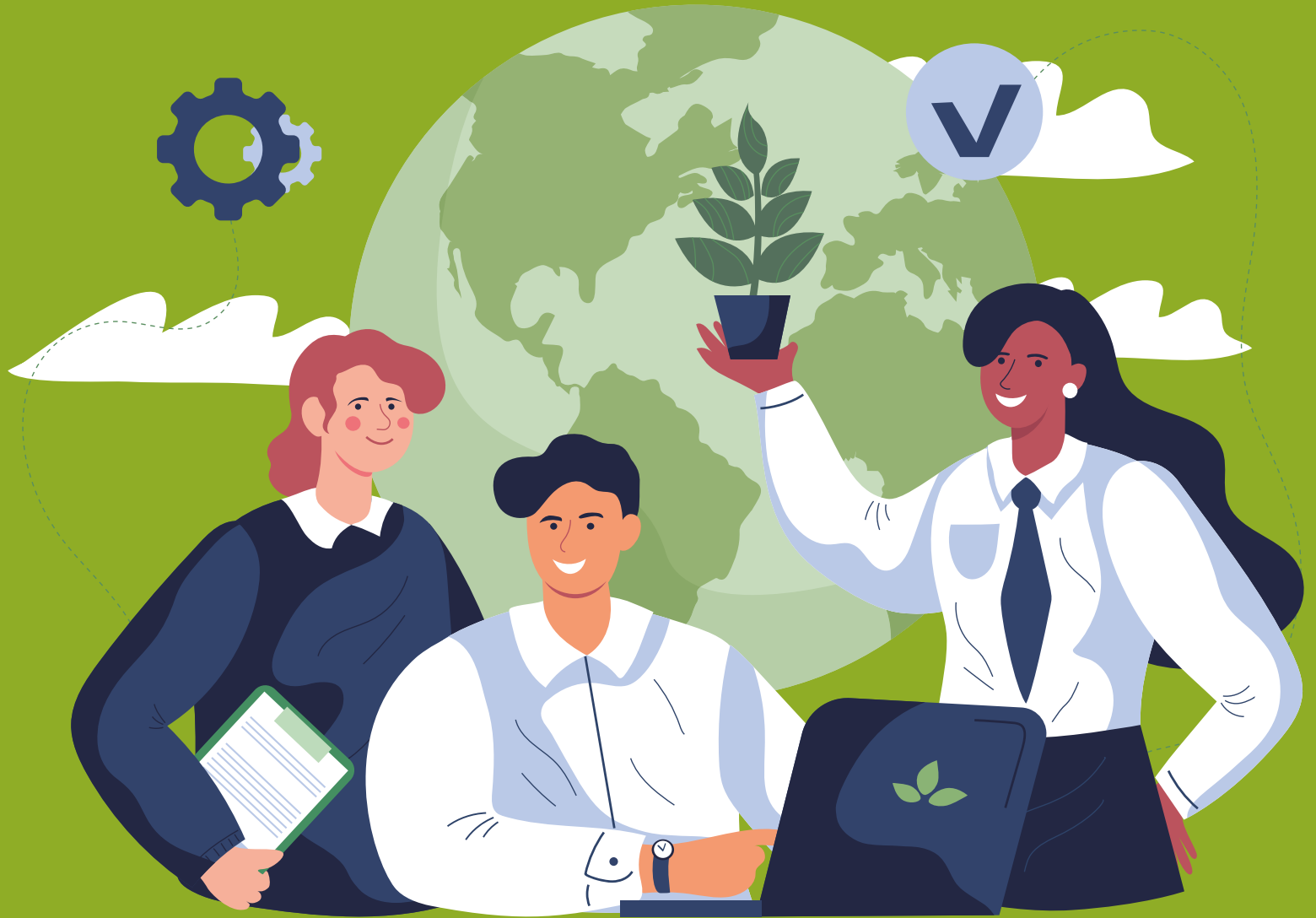

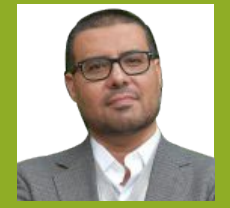

Víctor Muñoz PhDManagement, Departamento de Gestión y Negocios

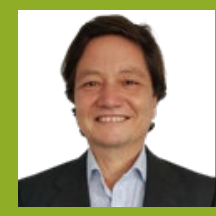

Cristian Geldes PhD Management, Departamento de Gestión y Negocios

En los últimos años se ha instalado la discusión del rol de las empresas en nuestra sociedad. Este debate ha sido impulsado por casos de colusión, corrupción, daño medioambiental y nuevas exigencias de los consumidores. Se han desprestigiado algunas empresas y se ha cuestionado la legitimidad del sistema económico. Lo anterior, a pesar del innegable desarrollo y bienestar que se ha logrado en las últimas décadas. Por supuesto, las causas de las diferencias entre las expectativas sociales y los resultados económicos son múltiples. En este artículo, planteamos que uno de los orígenes de esta dicotomía radica en la concepción de valor que ha guiado a las actividades empresariales.
\end{abstract}

\section{¿Qué es el valor?}

a búsqueda de valor es un tema central para las empresas, pero ¿qué es el valor? ¿qué supuestos subyacen a la concepción predominante de valor? y ¿cuáles son sus implicancias para la gestión estratégica de empresas? Como mostraremos a continuación, si los administradores no comprenden el concepto de valor, podrían debilitar la posición competitiva de la empresa y perder legitimidad debido a que sus decisiones no son percibidas como un aporte para el bienestar para la sociedad.

En las sociedades occidentales y, por cierto, en las escuelas de economía y negocios, se ha entendido que el rol de las empresas es crear valor mediante la provisión de bienes y servicios para luego capturar una parte de ese valor. Esta función de producción requiere tomar recursos de la sociedad -materias primas, trabajo y capital- para generar bienes y servicios. Los propietarios de los recursos necesarios para la producción participan voluntariamente en las transacciones, y el precio que pagan los compradores por los productos y servicios refleja sus preferencias subjetivas (valor 
para los consumidores). La sociedad tiene un mayor bienestar debido a la actividad empresarial que ha generado bienes $y$ servicios cuya valoración social excede al costo de oportunidad de los recursos que fueron empleados en su producción. Entonces, se dice que la empresa ha creado valor. En esta visión tradicional, maximizar las utilidades es equivalente a maximizar el valor para la sociedad. Los accionistas o propietarios de la empresa son los titulares de los excedentes de la empresa, por lo tanto, maximizar las utilidades implica maximizar el valor de la empresa para los accionistas.

\section{Maximización de valor}

Esta perspectiva de maximización de valor como objetivo de la empresa tiene varias ventajas para la gestión empresarial (Jensen, 2010). Proporciona un criterio simple y directo para la toma de decisiones. La existencia de un único objetivo permite a los gerentes evaluar alternativas según su contribución a las utilidades. También, entrega una medida clara para evaluar el desempeño y controlar a los gerentes, reduciendo así el espacio para su discrecionalidad y la búsqueda de iniciativas personales que se alejen del interés de los propietarios.

Sin embargo, para que la "maximización del valor" sea equivalente a la "maximización del valor para la sociedad" deben cumplirse algunos supuestos (Jensen, 2010; Mazzucato, 2019). En primer lugar, se asume que las empresas no tienen el poder de mercado que les permita fijar precios o condiciones de intercambio diferentes a las que se obtendrían en un mercado competitivo. En segundo lugar, la producción de bienes y servicios no debe tener externalidades negativas, es decir, costos para la sociedad que no sean asumidos de forma privada por las empresas. Los defensores de la maximización de valor asignan al estado el rol fundamental de evitar el incumplimiento de estos supuestos, dejando a las empresas libres de mayores preocupaciones al respecto. No es difícil ver cómo el incumplimiento de estos supuestos en las acciones empresariales está detrás de cuestionamientos tales como la contaminación, los desechos y los sobreprecios.

Los modelos simples son preferibles a los complejos, siempre y cuando mantengan su capacidad para explicar la realidad. Lamentablemente, la maximización de valor en su versión tradicional pasa por alto elementos que son fundamentales en la gestión estratégica. Por cierto, los ejecutivos de las empresas toman o deberían tomar sus decisiones con el propósito final de contribuir a la creación de valor. Sin embargo, dirigir una empresa hacia la creación de valor, compitiendo en mercados y satisfaciendo las expectativas de la sociedad, requiere una mayor amplitud conceptual que incorpore una mirada más amplia que la tradicional de valor, haciendo referencia al rol que deben jugar las empresas en los nuevos desafíos de la sociedad como el desarrollo sostenible e inclusivo.

\section{Creación de valor en la estrategia empresarial}

El principal desafío que enfrentan los administradores estratégicos no es optimizar lo que ya hace la empresa, sino definir una teoría, o un conjunto de supuestos interrelacionados, sobre cómo crear un valor superior a los competidores, es decir, lograr una ventaja competitiva (Barney \& Hesterly, 2015; Drucker, 1994). En otras palabras, ganará la empresa con la teoría que mejor refleje su realidad competitiva. Esta teoría la llamamos estrategia de la empresa y está formada por una serie de hipótesis o supuestos -basados en la mejor evidencia disponible- sobre: a) el ambiente de la organización, es decir, la sociedad, el mercado, los clientes, las políticas e instituciones, la tecnología entre otras variables; b) la misión de la empresa y; c) las competencias o habilidades centrales necesarias para cumplir esta misión. Es debido a la naturaleza cambiante de la competencia y del entorno que no es posible conocer si la estrategia es correcta a priori, y por lo que se plantea que la estrategia es una teoría.

Si la estrategia es correcta, la empresa logrará crear valor económico. La estrategia de la empresa establece las relaciones causales que llevarán a la creación de valor económico. Si la empresa no entiende cómo se genera el valor, cuáles son sus determinantes, no podrá crear valor de forma sostenible. Kaplan y Norton plantea una serie de dimensiones o perspectivas que se interconectan para determinar la creación de valor económico de la empresa (Kaplan y Norton, 1996). El resultado económico/financiero de una empresa sólo se produce si ésta satisface las expectativas y necesidades de los clientes a través de una propuesta de valor atractiva para los consumidores. Esta propuesta solo puede ser cumplida si la empresa logra implementar adecuadamente los procesos internos que la soportan y estos procesos solo podrán mantenerse y desarrollarse en el tiempo en la medida que la empresa ha desarrollado un capital intangible -personas, sistemas y procesos organizacionales- que le permita renovarse y crecer. En definitiva, el desempeño económico de la empresa depende de su desempeño en otras dimensiones, incluyendo su capacidad de gestionar las relaciones con los stakeholders que pueden afectar la capacidad de la empresa para crear valor económico. No se puede crear valor económico sostenible ignoran-

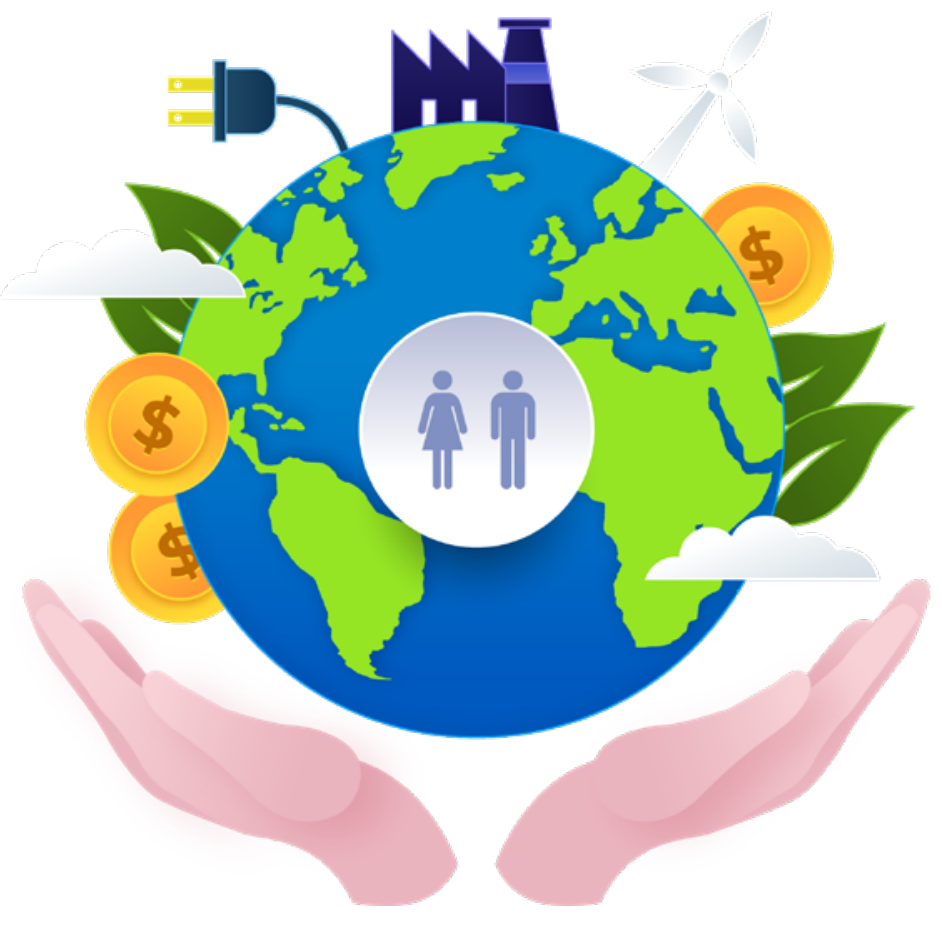


do, ni destruyendo sus determinantes.

Los defensores de la visión tradicional de valor rechazan la propuesta de Kaplan y Norton argumentando que plantear múltiples dimensiones de objetivo complejiza en demasía las decisiones empresariales que deberían tener un único marcador de logro. Kaplan y Norton responden con su clásico ejemplo en que comparan a una empresa con un avión cuyo piloto no podría llevarlo a su destino con un indicador único. Es necesario prestar atención a múltiples medidas, por ejemplo, altitud, velocidad y combustible. Es decir, no basta un único marcador (valor económico), sino que se requiere un tablero de control (cuadro de mando integral). Teniendo a la vista la complejidad del proceso de gestión estratégica, es evidente el atractivo que tiene para sus defensores la maximización de valor. El problema es que esta perspectiva no se hace cargo de la realidad en toda su complejidad.

Otro caso en el que vemos esta limitación es en el rechazo de esta visión tradicional a que la empresa tome en cuenta en sus decisiones a todos los stakeholders o partes interesadas que pueden afectar o verse afectados por las acciones de la empresa (Freeman, 2010). Entre los argumentos para este rechazo se encuentra la dificultad de los administradores para satisfacer múltiples objetivos, la falta de criterios guía para hacer elecciones entre favorecer a distintos grupos de interés contrapuestos, la discrecionalidad y la pérdida de control (Jensen, 2010). Estas preocupaciones son válidas, pero la realidad se impone y obliga a los gestores estratégicos a asumir la complejidad de su tarea. Cuando no lo hacen, destruyen valor aun cuando sus decisiones hayan sido orientadas por la visión tradicional de maximización de valor. Los millones de dólares en pérdidas que debieron asumir las empresas promotoras del proyecto $\mathrm{Hi}$ droAysén son un ejemplo claro de las consecuencias de ignorar los determinantes del valor ${ }^{1}$. Si bien el proyecto HidroAysén podía crear valor económico a partir de la generación de electricidad altamente demandada por el mercado chileno, e incluso valor para algunos actores de las comunidades locales, las empresas fallaron en reconocer que la valoración de amplios sectores de la sociedad sería tan negativa que motivaría una fuerte oposición al proyecto, haciéndolo inviable y llevando, en definitiva, a una destrucción de valor económico para las empresas promotoras.

\section{Maximización de valor ilustrada}

Las limitaciones de la visión tradicional de maximización del valor han llevado a que sus defensores propongan una versión modificada: la maximización de valor ilustrada (enlightened value maximization) (Jensen, 2010). Esta versión reconoce que es necesario orientar la conducta de las personas hacia la creación de valor en el largo plazo, abriendo la posibilidad de considerar asuntos de sustentabilidad, y el impacto de las actividades empresariales en los stakeholders. Se mantiene como propósito final la maximización del valor de la empresa, pero se reconoce explícitamente que esto no se puede lograr si se ignora o maltrata a alguno de los stakeholders principales (empleados, clientes, proveedores y comunidad). Sin embargo, se mantiene la posición de dejar en manos del gobierno el control del poder de mercado y las externalidades.

\section{Valor sostenible}

En la búsqueda de enfoques alternativos a la visión tradicional de creación de valor, surge el concepto de "valor sostenible" propuesto por Hart y Milstein (2003). El valor sostenible se entiende como las estrate-

Figura 1

Marco conceptual para la creación de valor sostenible (Hart y Milstein, 2003)

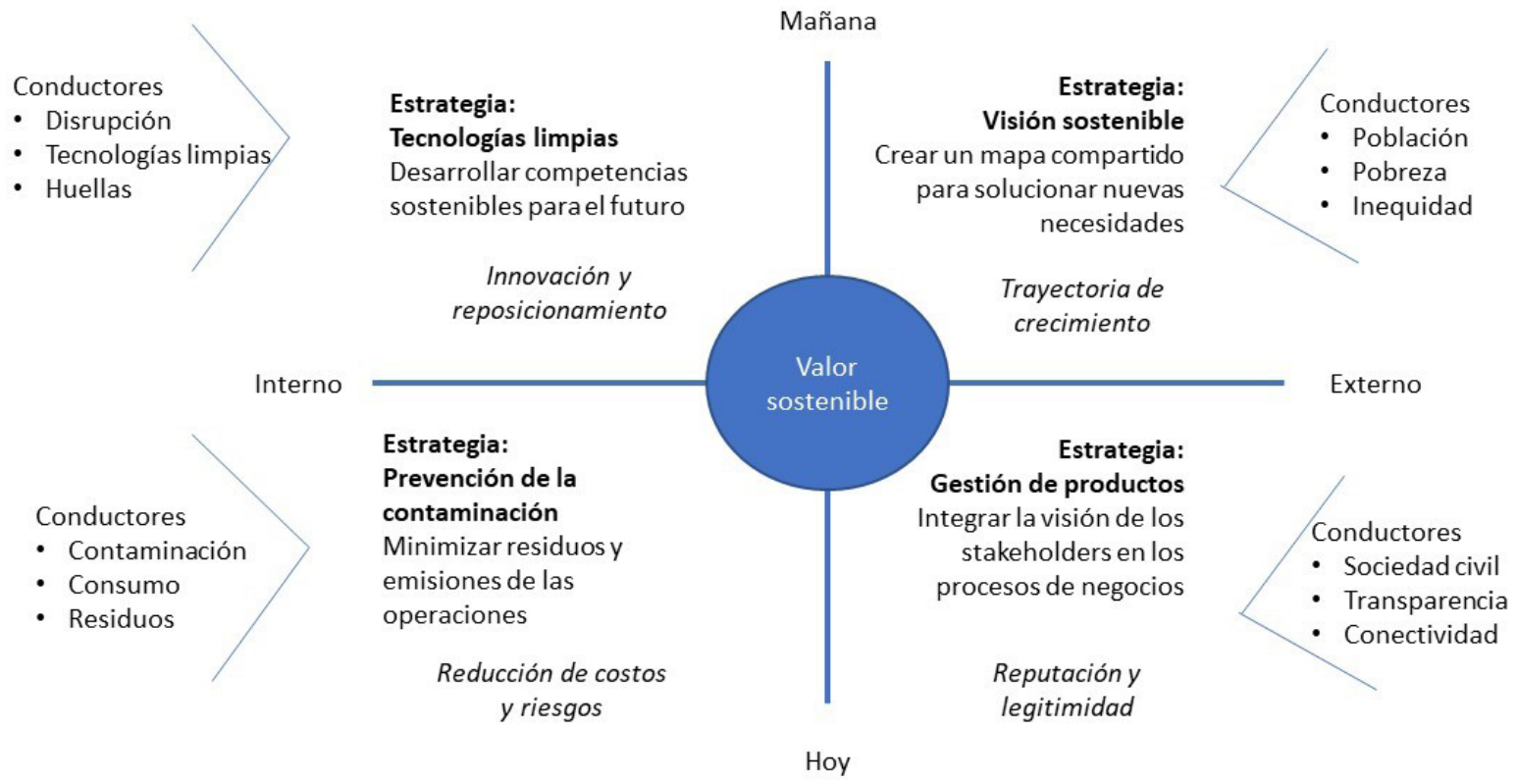

(1) https://www.latercera.com/noticia/los-numeros-detras-hidroaysen/ 


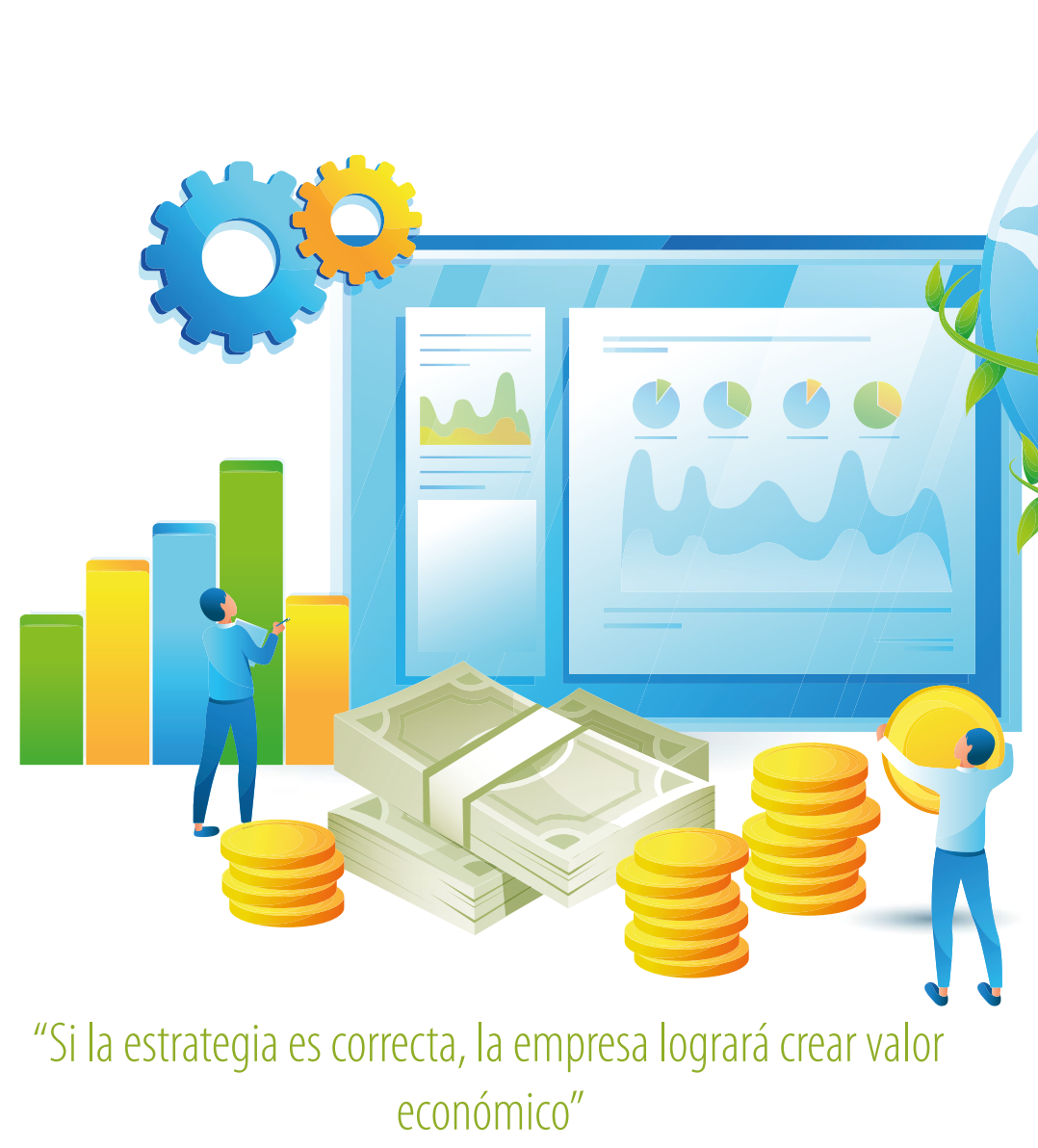

gias y prácticas empresariales que contribuyen a un mundo más sostenible y a la vez crean riqueza para los accionistas.

Para abordar el desafío de desarrollar la sostenibilidad como un problema complejo, multidimensional y crecientemente urgente, estos autores proponen un marco estratégico para las empresas que permite identificar estrategias que aborden las tensiones entre los ámbitos internos y externo, así como entre el hoy y el futuro, que permiten identificar cuatro cuadrantes como se identifica en la Figura 1: la innovación y reposicionamiento, la trayectoria de crecimiento, la reducción de costos y riesgos, y la reputación y legitimidad.

\section{Valor compartido}

Porter y Krammer (2011) plantean un enfoque de "valor compartido" que definen como "las políticas y prácticas operativas que expanden la competitividad de una empresa mientras simultáneamente se avanza en las condiciones económicas y sociales de las comunidades en las que opera". Básicamente, la creación de valor compartido se enfoca en identificar y expandir las conexiones entre el progreso económico y social, ya que la competitividad de una empresa y la salud de las comunidades donde opera están fuertemente entrelazadas. Una empresa necesita una comunidad exitosa, no sólo para crear demanda de sus productos, sino también para brindar activos públicos cruciales y un entorno que apoye el negocio. Las empresas deben reconectar su éxito de negocios con el progreso social. El valor compartido no es responsabilidad social ni filantropía y ni siquiera sustentabilidad, sino una nueva forma de éxito económico.

\section{Conclusión}

Es evidente que el rol de las empresas y la creación de valor son elementos centrales del management. Ambos evolucionan hacia nuevos enfoques como el valor sostenible y valor compartido y se vinculan directamente con los desafíos de la sociedad, en especial con el desarrollo sostenible (Lubin y Esty, 2010); que generalmente se ha entendido como abordar los procesos de toma de decisiones empresariales incorporando lo económico, social y ambiental (triple bottom line), junto con crear nuevos modelos de negocios sostenibles como son los de economía circular, aquellos relacionados con nuevas tecnologías e innovaciones, y nuevas formas de gobierno (Slaper y Hall, 2011; Lewandowski, 2016; Salvia et al, 2019).

\section{REFERENCIAS}

- $\quad$ Barney, J., \& Hesterly, W. (2015). Strategic Management and Competitive Advantage. Pearson.

- Drucker, P. (1994). The Theory of the Business. Harvard Business Review, 75, 95-105.

- $\quad$ Freeman, R. (2010). Strategic management: A stakeholder approach. Cambridge University Press.

- Hart, S. L., \& Milstein, M. B. (2003). Creating sustainable value. Academy of Management Perspectives, $17(2), 56-67$.

- Jensen, M. C. (2010). Value Maximization, Stakeholder Theory, and the Corporate Objective Function. Journal of Applied Corporate Finance, 22(1), 32-42. https:// doi.org/10.1111/j.1745-6622.2010.00259.x

- Kaplan RS, Norton DP. Linking the Balanced Scorecard to Strategy. California Management Review. 1996;39(1):53-79. doi:10.2307/41165876

- Lewandowski, M. (2016). Designing the business models for circular economy-Towards the conceptual framework. Sustainability, 8(1), 43.

- Lubin, D. A., \& Esty, D. C. (2010). The sustainability imperative. Harvard business review, 88(5), 42-50.

- Mazzucato, M. (2019). El valor de las cosas. Quién produce y quien gana en la economía global. Taurus.

- $\quad$ Porter, M. E., \& Kramer, M. R. (2011). Creating Shared Value: Harvard Business Review. Jan-Feb, 2011, 1-17.

- Salvia, A. L., Leal Filho, W., Brandli, L. L., \& Griebeler, J. S. (2019). Assessing research trends related to Sustainable Development Goals: Local and global issues. Journal of cleaner production, 208, 841-849.Slaper, T. F., \& Hall, T. J. (2011). The triple bottom line: What is it and how does it work. Indiana business review, 86(1), 4-8. 